\title{
Side Effects of National Immunization Program: E-Governance Support Toward Seniors' Digital Inclusion
}

\author{
Magdalena Ciesielska \\ Gdańsk University of Technology \\ magdalena.ciesielska@pg.edu.pl
}

\author{
Nina Rizun \\ Gdańsk University of Technology \\ nina.rizun@pg.edu.pl
}

\author{
Anna Baj-Rogowska \\ Gdańsk University of Technology \\ anna.baj-rogowska@pg.edu.pl
}

\begin{abstract}
In response to the coronavirus pandemic, the European Union (EU) governments develop policies to regulate exclusive health protection actions that consider societal needs with the emphasis on elders. Given that the EU vaccination strategy uses a centralized ICT-based approach, there is little guidance on how seniors are included in national immunization programs (NIP). In this paper, we addressed a knowledge gap of the side effects of $e$ governance of NIP for the elderly. To fill this gap, we identified 40 side effects by analyzing online textual opinions (tweets, comments, articles) that express public perception regarding the results of the Polish NIP implementation to seniors' digital inclusion, categorized them into 8 categories and assign them to four e-governance functions. The main contribution of this paper is a better understanding of the digital divide and to provide guidelines for government policy improvement.
\end{abstract}

\section{Introduction}

As the Covid-19 pandemic hit European Union (EU) countries, governments faced an undoubted challenge to provide public value, under a fast response time and strict social supervision. The benefits of e-government such as transparency, functionality, accessibility, usability [1], efficiency, effectiveness, service quality, interoperability [2] have never been tested on a large scale by societies. Since seniors are the most affected group by the Covid-19 [3] it is substantial to satisfy this social group's need regarding health protection. Health statistics indicate around $80 \%$ of the deaths due to Covid-19 occur in the 65+ group [4]. Moreover, social isolation mostly affects seniors [2]. In consequence, technology became the source of contact of elders with the external world, and governments face challenges to reflect changes in social relations between government and citizens [5].
In response to the Covid-19 pandemic, governments create policies, constitute exceptional regulations, governing and managing actions to protect citizen health. Despite the effort, vaccine rates are still low, and far from desirable, and the effectiveness of EU Member States vaccination policies vary [6]. Countries such as Denmark, Ireland and Spain, manage to immunize (first dose) all 80year-old citizens. The slower vaccination process characterizes Poland, Latvia and Bulgaria, p.e. in Poland only $58.2 \%(60+)$, and $58.6 \%$ (80+) seniors received the first dose [7]. Having in mind that the EU immunization strategy is based on a centralised, ICTbased approach, there is little guidance on how the public policy includes seniors in national immunization programs (NIP).

Based on the above motivation, the main objective of this study is to provide insights into the side effects of NIP concerning e-governance to support the digital inclusion of elders. The research objective is investigated by the following research questions (RQ): 1) What are the side effects of the national immunization program for seniors? 2) How are the side effects of national immunization program for seniors grouped into categories? 3) Which egovernance functions respond to the side effects of the national immunization program for seniors? To answer these research questions, we adopted a twofold approach, including analytics-driven (topic modelling) and expert analysis methods. To identify side effects of NIP of seniors, the case study of Polish Covid-19 vaccination program experience, discussed on Twitter, Polish news, and medical portals, is used. As a result, this study provides 40 side effects of the NIP of elders exclusion grouped into 8 categories and analyzed versus e-governance functions. This paper contributes to a better understanding of issues influencing seniors' exclusion that emerged in the process of NIP implementation and to provide guidelines for such program's improvement.

The structure of this paper is as follows. Section 2 provides a theoretical background on the 
digital exclusion of seniors and governance of Covid19 pandemic for elders. Section 3 includes the methodology adopted in this study. Section 4 presents the results. Section 5 provides discussion, while Section 6 concludes the study.

\section{Background}

This section provides a background to a study based on the literature review including the digital exclusion of seniors (Section 2.1), and governance of Covid-19 pandemic for seniors (Section 2.2.).

\subsection{Digital exclusion of seniors}

Technological development facilitates the provision of public services, however one of the main side effects of ICT use is the digital divide [8]. OECD [9] defines the digital divide as "the gap between individuals, households, businesses, and geographic areas at different socioeconomic levels with regards both to their opportunities to access ICT and to their use of the Internet for a wide variety of activities". Scholars point to a broad range of socio-economic factors lying at the fundamentals of the digital divide such as age, low income, education level, sex, race, social class, employment status, literacy level [11]. However, the digital divide caused by age has become a particular issue of scientific investigation [12]. On one hand, seniors constitute $20.3 \%$ of the EU society [13], becoming one of the largest target markets for eservices and beneficiaries of e-government [14]. Conversely, seniors demonstrate a low interest in digitalization and Internet use [15], and technological adoption lag is high [14]. Scholars identify multiple reasons for not using the e-government services by the elders including lack of Internet access [16], complex usage [19], the necessity to learn [19], fear of technology and security [20], social isolation [14] and limited awareness of the e-government benefits, lack of trust [20]. Thus, mitigating the effects of the digital divide among seniors, the government's focus is on the provision of accessibility, awareness building, socialization techniques, training and motivational programs [22].

\subsection{Governance of Covid-19 pandemic for seniors}

The ability of the State government to cope with unexpected and risky issues [23], and to satisfy high expectations of public and various institutions [24] is crucial. The e-governance concept [25] includes egovernment service provision, forcing a new style of leadership [26], new transactional processes [27], new information distribution, building societal engagement [28], and adoption of citizen-centric approach [29].

Global pandemic resulted in the rapid rise of ehealth due to the lockdown constraints, and adoption of the centralized immunization distribution system [30] due to the limited supply. In the EU the vaccination is governed within the Member States' legal frameworks following NIPs. According to [31] the Member States are to set a centralised structure toward the vaccination distribution, to set a central point of contact, to provide clear and timely access through relevant media to information, to ensure Electronic Immunisation Information System or vaccination registries are in place, and to institute recall system. The vaccination process for elders $(60+)$ defined as a priority group follows the order of immunizations announced by the State government [30] and is heavily supported by e-health [32]. Even though the advantages of e-health are known [33], its effectiveness is impeded since $40 \%$ of seniors lack the skills to use telehealth resources [34]. While seniors are only passive users of mobile phones [35], and the main driver for seniors' Internet usage is performance expectancy [36], the inclusion is facilitated by the design of a user-friendly interface [17], bringing comfort and trust [33], and use of telehealth platforms, promising inclusion of rural populations [37]. The above means are proven to be missing the point since the digital divide in health is widening due to environmental, social, economic, political and community contexts [38].

Summing up, the global pandemic has revealed the importance of digital inclusion of elders since seniors are (1) highly represented group in national demographics of the EU member states, (2) mostly endangered to Covid-19, and (3) vulnerable apart from the national health protection system due to the digital exclusion, which is particularly aggravated by the transfer of the majority of medical services to e-health during the pandemic. Moreover, since the Covid-19 pandemic is not globally under control, governments still seek effective levers and tools for adaptive governance and adjustment of emerging side effects of national politics.

In this context, our analysis of the literature revealed the following knowledge gaps: (1) despite the active use of public opinion for the government policy shaping, no in-depth research has been carried out to identify the side effects of the NIP's implementation among seniors based on freely available online textual comments, opinions, reviews, articles; (2) despite the well-known recognition of the digital divide's phenomena regarding e-government services and the requirements for social inclusion policies, as to date 
there are no guidelines to e-governance and counteracting of such side effects of NIP's implementation for elders.

\section{Methodology}

This section aims to describe the research methodology adopted in the current study. Section 3.1. provides information on the method of the case study data collection. Section 3.2 describes the data analysis.

\subsection{Data collection and preparation}

To identify the core side effects of the NIP regarding for seniors, Polish Covid-19 NIP's experience is selected. Three-fold data sources are adopted to gain a full understanding of the successes and challenges faced by the e-government to include seniors into the vaccination process: (1) Twitter (public tweets); (2) Polish news portals (public comments) ${ }^{1}$, and (3) Polish medical portals (public articles, reviews, interviews $)^{2}$. The choice of Polish experience as a research object of Covid-19 immunization program, and the specific social media set as a data source of our study, is motivated by several factors.

First, according to statistics: (i) Poland is a typical example of an aging society where median age in 2019 was 41.3 for men and 42.6 for women ${ }^{3}$; (ii) around $80 \%$ of the deaths due to Covid-19 occur in the 65+ group [4], (iii) the effectiveness of the vaccination programme in Poland compared to EU countries is still quite poor [7]. On the other hand, Electronic Government Digitization Index of Poland characterizes steady progress over the past ten years, both in the value $(0.85$ in 2020$)$ and in ranking position $\left(24^{\text {th }} \text { in the } 2020 \text { ranking }\right)^{4}$. Thus, the Polish experience allows us to adequately demonstrate the side effects of homogeneous government regulations on the vaccination that (i) arise despite the moderate initial prerequisites for the level of digitalization, and (ii) promise to be relevant for the government use in other EU countries.

Second, (i) although Facebook is the largest social networking site in terms of reach and popularity, Twitter dominates the sphere of public life around the world [39]; (ii) despite the fact that $58.7 \%$ of Polish Twitter audience composed of users aged between 18

\footnotetext{
1 i.e. gazeta.pl, biqdata. wyborcza.pl, next.gazeta.pl

2 i.e. medonet.pl, mp.pl, abczdrowie.pl

3 https://www.statista.com

${ }^{4}$ https://publicadministration.un.org

5 https://www.statista.com

6 "szczepimy" (Polish)
}

and 44 years old ${ }^{5}$, every year Polish seniors are more and more active in social media, and we meet them on Twitter now(14.3\%) more often than on Facebook (10.6\%) [40]; (iii) the potential of Twitter platform is noticed not only by ordinary users but also by state bodies, ministries, various offices, and political decision-makers as a news medium whose functions work very well as an intermediary for sharing 'hot' news, monitoring online public opinion, governmentcitizen interaction and influencing public policymaking [41]; (iv) as confirmed by numerous studies, social media data are useful to obtain valuable, realtime insights into attitudes toward Covid-19 vaccines to better understand public attitudes and sentiments about vaccines, discover policy weaknesses, and improve public value delivery [32]. According to [42] it is possible to get insights into NIPs from a quick international comparison of public comments on Twitter. Early information about vaccine hesitancy and anti-vaccination attitudes from Twitter data affect the decision-making process [43] and serve as an input to organize the preventive measures. Thus, Twitter comments data source, supplemented by national news and medical online portals, in comparison with prestructured questionnaires, has significant advantages, expanding both the respondents audience sharing their experiences (seniors, their family members, healthcare workers, politicians, etc.), and the scope of unexpected research insights [44].

QDA Miner software is used for text data scraping. Our search for text data is limited to a query: "vaccination" OR "vaccine" OR "covid-19" OR "coronavirus"7 OR "Pfizer" OR "Moderna" OR "AstraZeneca" OR "Johnson\&Johnson" AND "senior*". In total, we collected 50,726 tweets, which all texts are in Polish. The period for tweets scraping is $1^{\text {st }}$ May till $31^{\text {st }}$ May 2021. Next, the text preprocessing steps are performed. Python and $\mathrm{R}$ libraries are applied. We removed duplicate and empty tweets, and invalid data; performed text cleaning ${ }^{8}$ and words lemmatization 9 . A set of 12,592 tweets is obtained. Next, we detect the language of the tweets ${ }^{10}$ and retain tweets in Polish resulting in a dataset with 11,533 tweet documents. The same procedure is applied to the other two data sources. Finally, a set of (1) 624 comments from Polish news portals (period for comments scraping is $1^{\text {st }}$ January till $31^{\text {st }}$ May 2021, 444 comments after text preprocessing), and

\footnotetext{
7 "koronawirus" (Polish)

8 tm package

9 Morfologik Lexicon

10 cldr language detection
} 
(2) 373 articles from Polish medical portals (period for comments scraping is $1^{\text {st }}$ January till $31^{\text {st }}$ May 2021, 265 articles after text preprocessing) is established. Thus, three separate preprocessed datasets were included for further data analysis.

\subsection{Data analysis}

To derive the main research findings, the following qualitative and quantitative textual data analysis steps are realised.

First, to answer RQ1, the Latent Dirichlet allocation (LDA) topic modelling algorithm ${ }^{11}$ is employed to extract the latent topics in the public comments/articles on the NIP toward seniors and their proportions. For the Twitter dataset, the 40-topic model is found to be optimal in terms of the average semantic coherence of the models. As a result of LDA models running, 40 topics, described by the topweighted keywords and a set of documents, mostly associated with this topic are obtained. To interpret the results, the iterative process of topic labelling is performed: (1) experts independently performed the deep reading and coding labelled topics to create the first version of labels based on the keywords with the highest weight; (2) the experts discussed labels and refined topic labels by a deep reading of the most representative topic comments; (3) the experts jointly agreed on and described a final set of topic labels. As experts, three academics specialized in e-government and its transformation, and experienced in coding, interpreting and analysis of the unstructured (textual) data, are involved. The same topic modelling and labelling procedure are applied to the other two datasets. Ten topics for each dataset are extracted and labelled. Obtained 60 latent topics are analyzed by experts and partly merged with the aim, to eliminate duplicate labels/content, and finally, a list of 40 side effects of the NIP of seniors is formed. The proportions of the merged topics have been summed up (with preliminary numbers normalization). Then, the sentiment analysis of texts for each topic is performed. For this step, Polish Sentiment Lexicon ${ }^{12}$ is used as a list of expressions annotated according to affect positive or negative categories [45]. As a result, a binary classification (positive/negative sentiment) for each of the 40 side effects is performed.

Second, to answer RQ2, we employ coding to identify relevant interactions between the topics and aggregate them into higher-order concepts (categories). For this purpose: (1) the experts independently analyzed the presence of the contextual

\footnotetext{
11 LDA topicmodels

12 Polish Sentiment Lexicon
}

similarities between side effects labels to produce the first version of groups; (2) the experts discussed the categories and resolved discrepancies in the topic grouping; (3) the experts validated the groupings by triangulation with findings from extant studies on seniors e-government exclusion; (4) the experts agreed on final side effects' structure. As a result, eight categories of side effects are identified. Two of them are introduced in addition to the existing results of previous studies.

Third, to answer RQ3, the experts assigned side effects to e-governance functions to support the seniors' inclusion in the NIP. Four e-governance functions are formulated based on the legal normativity approach [46]. During the assigning process, we assume that one side effect could be addressed by several e-governance functions. The statistical analysis was conducted of the side effect structures to reveal the presence of patterns; for instance, the distribution of e-governance functions across the derived side effect categories.

\section{Results and findings}

This section presents the main results of this study. The results include the analysis of the side effects of the NIP for seniors (Section 4.1); the categories of side effects of NIP for seniors (Section 4.2); and e-governance function to support NIP for seniors (Section 4.3).

\subsection{Side effects of national immunization program for seniors}

This section provides an answer to the research question RQ1: What are the side effects of the national immunization program for seniors? The answer deepens our understanding of what side effects of NIP implementation are concerning public perception, expressed in social media. In total, 40 side effects are identified. The top five most important side effects account for $26.92 \%$ of the analyzed tweets (comments, articles) are presented in Table 1. The full list of identified side effects, their topic proportion (TP, \%) and selected comment's examples is a part of the supplementary material ${ }^{13}$. Side effects associated with positive sentiment account for only $7.02 \%$ of the comments in our dataset (five topics) and mostly include informational posts (comments), containing announcements, data facts about conditions for the delivery, storage and distribution of vaccines; vaccine biological mechanisms and production process;

${ }^{13}$ List of Topics and Comments Examples 
incentive measures for people's engagement to the vaccination; and seniors digital skills training.

Table 1. Top-5 side effects of the NIP for seniors

\begin{tabular}{|l|r|}
\hline Side Effect & TP, \% \\
\hline $\begin{array}{l}\text { Limited or no access to Internet and/or Mobile } \\
\text { phone }\end{array}$ & 7.03 \\
\hline $\begin{array}{l}\text { Poor organization of the vaccination in rural } \\
\text { and remote areas }\end{array}$ & 5.25 \\
\hline $\begin{array}{l}\text { Poor quality of the official statistical data on } \\
\text { governmental websites }\end{array}$ & 5.03 \\
\hline Need for mobile (home) vaccination teams & 4.88 \\
\hline Collective social responsibility & 4.73 \\
\hline
\end{tabular}

\subsection{Categories of side effects of national immunization program for seniors}

This section answers question RQ2: How are side effects of national immunization program for seniors grouped into the categories? We identify eight categories to represent the side effects: (1) Accessibility, (2) Awareness, (3) Engagement, (4) Data governance, (5) Distribution, (6) Trust, (7) Intermediaries support, and (8) Citizen rights. Each category covers specific, non-repetitive content. The first six categories are covered in research related to the issues of mitigating the effects of the seniors' digital exclusion regarding e-government [47]. However, the last two categories are a result of our study, expanding understanding of the most relevant factors of seniors' exclusion resulting from NIP and to provide a solid foundation for its improvement. Figure 1 demonstrates the degree of importance for the citizens of unresolved side effects of each category (based on topic proportions). The full list of the identified categories of the side effects is a part of the supplementary material ${ }^{14}$.

Following characteristics of categories include description, content and proportion in the merged comments dataset:

1) The Accessibility category as a public policy objective is to provide ICT infrastructure, its availability and technology acceptance by the elders to use e-government services [14]. This category of the NIP side effects includes "Limited or no access to Internet and/or Mobile phone", "Poor quality of telemedicine and virtual care" and lack of "Seniors digital skills training". It represents $8.55 \%$ of all analyzed opinions.

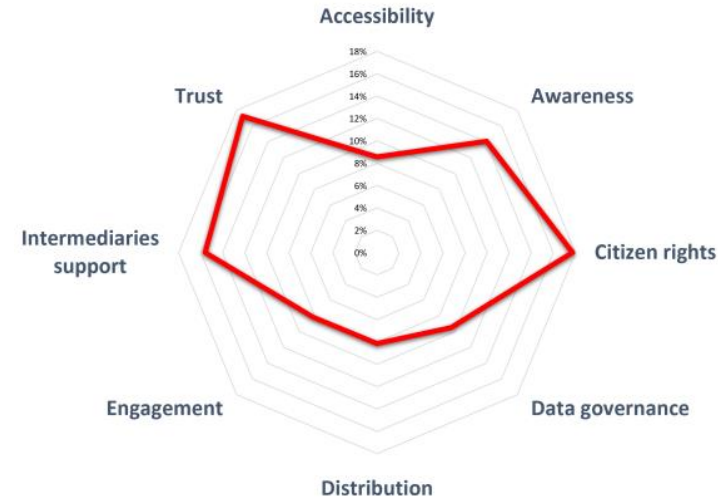

Figure 1. Coverage of the side effects by categories

2) The Awareness category as a public policy objective, is to provide continuous information flow to build awareness of NIP, its changes, and implementation, to both (i) a specific target group, characterized by an increased level of mistrust to changes, and new information sources [48], and (ii) a high degree of uncertainty and dynamic situation of Covid-19, that turned out to be limitedly effective and does not satisfy the needs of the population to be aware of: "Details of the NIP and vaccination points", "Local and systemic vaccine adverse reactions", "Vaccine biological mechanisms and production process", thus leading to "Low consciousness regarding the vaccination". This category represents $14.06 \%$ of all analyzed opinions.

3) The Engagement category as a public policy objective aims to involve seniors in civic activity to fulfil significant civilian roles for leisure or industrial activities [49]. Regarding NIP, seniors search for special "Incentives to the vaccination" and "Contextualized marketing campaigns" to overcome "Hesitation toward the vaccination". This category represents $8.20 \%$ of all analyzed opinions.

4) The Data governance category as a public policy objective is to define, apply and monitor the patterns of rules to control and ensure proper data quality and compliance with relevant legal and ethical requirements to guarantee that trustworthy decisions are made [50]. During the implementation of the NIP, unresolved data governance aspects are "Uncertainty and inconsistency of information due to dynamic data change", "Poor quality of the official statistical data on governmental websites", and "Need to monitor, collect and study data on vaccine side effects". This category represents $9.50 \%$ of all analyzed opinions.

5) The Distribution category involves fulfilling public policy objective to provide distribution channels of medical products and healthcare services,

\footnotetext{
${ }^{14}$ Side Effects Categories
} 
which regarding seniors' perception of NIP expresses a need to resolve "Vaccine logistic issues", maintain required "Conditions for the delivery, storage and distribution of vaccines ", and avoid "Messy in the schedule" of the vaccination service delivery. This category represents $8.13 \%$ of all analyzed opinions.

6) The Trust category as a public policy objective is aimed at creating a comprehensive trust and confidence in the NIP and thereby increasing the degree of willingness to participate in this program [51]. The main obstacles to the formation of the necessary degree of trust and confidence in the seniors' NIP according to social network users are (i) "Resistance to the vaccination" due to (ii) "Fears of severe effects of the vaccination", "Vaccine quality" and "Increased deaths after the vaccination", (iii) "Limited relevant information on COVID mutations" and (iv) "Lack of tests before the vaccination", as well as information distortion due to the presence of (v) "Fake medical and political news" as well as cultural characteristics of the elderly, such as (vi) "Seniors religiosity". This category is the second in terms of the number of analyzed public opinions $-17.23 \%$.

7) The Intermediaries support category as a public policy objective is to facilitate NIP implementation by bridging the gap between the government providers and seniors needs and requirements [52]. Considering the complexity of seniors' digital exclusion, and NIP implementation, the call for intermediary support to elders becomes especially acute, which explains the emergence of this additional category as a result of our study. Among the side effects of NIP, public discussion aroused around "Poor organization of the vaccination in rural and remote areas", "Difficulties to identify and localize seniors in urban area", "Limited support toward disabled elders", "Need for the mobile (home) vaccination teams", "Ineffective recall system and support", and "Direct or telephone contact". This category is the third in terms of the number of analyzed public opinions $-15.59 \%$.

8) The Citizen rights category as a public policy objective consists of the government's obligation to ensure the observance of all citizens' rights by the State. In the context of the NIP implementation, introducing this category expands understanding importance of these aspects, unseen by the NIP as "Lack of insurance or the severe vaccine adverse reactions", "Suspended treatment of cancer patients", "Violation of freedom by compulsory vaccination", "Discrimination against people, who are not vaccinated", and "Forcing employees to get vaccinated", and the critical need to awaken and intensify "Collective social responsibility", and also "Lack of government openness and transparency". This category is the most crucial in terms of the number of analyzed public opinions $-17.74 \%$.

\subsection{E-governance functions to support the vaccination of seniors}

This section answers the question RQ3: Which egovernance functions respond to the side effects of the national immunization program for seniors? Given the complex nature of e-government service provision toward elders, incorporating both governance and egovernance concepts, we look at the phenomena from a functional point of view.

The literature distinguishes various e-governance functions such as policy-making, regulation, and eadministrative service delivery [53]; or policymaking, regulation and operations [13]. We use legal normativity approach [46] in this study to define four e-governance functions (EGF). The first function protective - is to protect the public value by the legal solutions, expressed by the protection of individual and public social interests, and assigning extra permission to the "weaker party", and their protection. The second function - organizational - is to organize a social life by the structure, governance, and management of various social life dimensions, and to assign legal responsibilities to public institutions. The third function - informational - is to shape positive attitudes toward legal regulations as a means of an expression of social policy objectives, or public value protection (p.e health, equality, freedom etc.). The transactional function is accomplished via the $\mathrm{e}$ administrative process, as an effective instrument of public value provision.

We assigned 40 side effects to four e-governance functions. Each side effect could be addressed by several EGFs. As a result, the largest number of side effects is associated with the implementation of the Informational EGF $(46.77 \%)$, in the second place is the Organizational EGF (24.19\%), then the Protective and Transactional EGFs address each by $14.52 \%$. The full results of the side effects assigning to EGF are a part of the supplementary material ${ }^{15}$.

The EGFs regarding determined side effects are described as follows, covering the structure and the most significant content.

Informational function. This research identifies 29 side effects to be mitigated by informational EGF. This function is the primary one to solve most of the side effects, being present in the 7 out of 8 categories

\footnotetext{
15 Side effects assigned to E-government functions
} 
(except for "Distribution"). In “Awareness", "Engagement", and "Trust" categories informational EGF addresses all of them. The most significant side effects assigned to this category are (1) "Poor organization of the vaccination for seniors of rural and remote areas" - low senior awareness on the conditions, possibilities, benefits of immunization, and lack of recall system; (2) "Poor quality of the official statistical data on governmental websites"; (3) "Collective social responsibility and assistance to the elderly" - social responsibility expressed by informing the institutions about seniors who live nearby and are willing to vaccinate at home; assisting seniors with relevant information on the vaccination process, direct help with registration and mobility.

Organizational function. This study identifies 15 side effects to mitigate by organizational EGF. This function responds to 6 out of 8 side effects categories. It fully covers the side effects in the "Distribution" and "Intermediaries support" categories. The most significant side effect is a need to respond to a limited number of the vaccination points, and long queues particularly in "Rural and remote areas". Three urgent side effects are a necessity to organize the established system to "Mobile (home) vaccination teams" and "Direct (or telephone) contact with seniors for vaccination", and fixing "Messy scheduling" problems, thereby limiting administrative burden of healthcare (p.e. calling seniors, providing explanatory information, psychological assistance).

Transactional function. Nine side effects to mitigate by transactional EGF are identified. This EGF appears in 4 out of 8 categories. Primarily, enabling to solve "Limited or no Internet, and/or Mobile phone" pointing to difficulties of using mobile phones, even at a basic level; the use of only stationary telephones; the absence of Internet and electronic services or lack of digital skills; problems with hearing, vision, limited movement and other forms of disabilities, which also limit the possibilities of using digital technologies.

Protective function. Protective EGF mitigates 9 side effects and responds to only in 2 out of 8 categories, fully covering "Citizen rights" and "Intermediaries support" side effects. Obtained results indicate the most important side effect is "Lack of insurance or the severe vaccine adverse reactions". Since some seniors cannot be vaccinated due to medical contraindications, their dissatisfaction concerns address "Discrimination against people, who are not vaccinated" and requires complex targeted protective and informational support.

Figure 2 depicts the distribution of the side effects categories across all EGFs. This distribution, (i) identifies the main components of the side effects for each EGF; (ii) provides information on the degree of importance to each EGF responding to the side effects; (iii) builds understanding on the degree of impact and complexity of each side effects' category in terms of need to involve various EGFs to resolve them. X-axis displays the proportion of the side effects of each category that are assigned to the E-governance function (\%). Y-axis presents the importance of the Egovernance function responding to side effects from each category (based on the number of side effects assigned to each EGF, weighted by the proportion of comments in which the side effect was discussed).

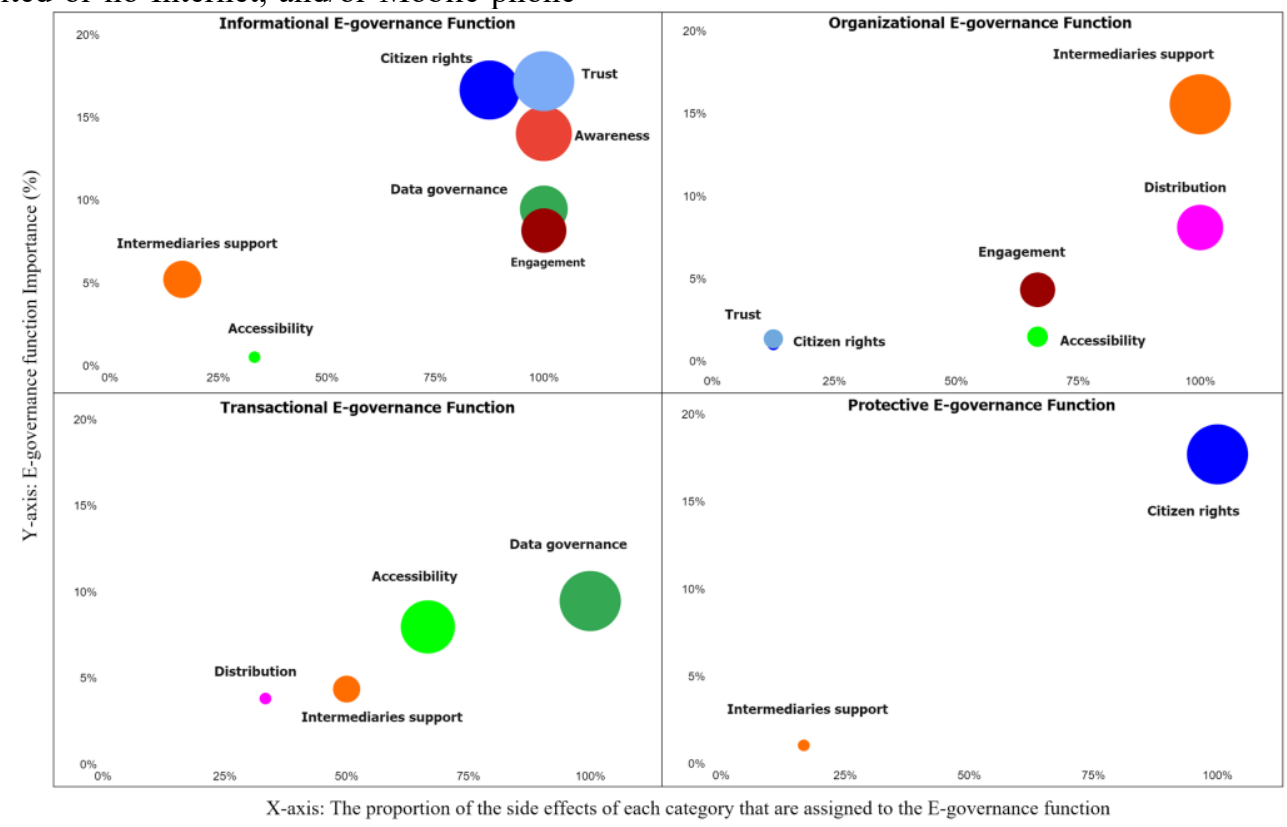

Figure 2. Distribution of the side effects categories by e-governance functions 


\section{Discussion and recommendations}

In this paper, we addressed a knowledge gap of the side effects of e-governance of national immunization program for seniors. To fill this gap, we identify 40 side effects by analyzing text comments (articles, reviews) that express public perception regarding the results of the Polish NIP implementation to seniors' digital inclusion, categorizing and assigning them to four e-governance functions.

We understand e-governance functions as such, that result from the social contract between the citizen and the State, and are reflected in the normative acts. The legal normativity approach [46] relates to the functions of law, but we see the possibility of its application to the e-governance concept since its execution must follow the legal rigor.

The main methodological contribution of our work is to demonstrate how text analytics methods are successfully used to extract deep insights from online available public feedback to complement data obtained from carefully designed surveys [42]. We introduce a unique categorization of the side effects of NIP for seniors providing data on the degree of importance of the side effects in each category through citizens' experience. In line with [43] this can serve as the input to adapt inclusion and e-health policy into egovernance of the immunization of seniors.

Within a case study our results support findings of [54] as to the limited accessibility of elders to the Internet, lack of mobile phones [12]; lack of good quality statistical data on governmental websites [48], poor e-health telemedicine and virtual care quality [55]. The results confirm the importance of issues like accessibility, engagement, and data governance to elders' inclusion in line with [12].

Filling the gap in existing literature, our results shed light on the acute need to increase social responsibility to the seniors' inclusion in NIP. According to our results performing the informational function, public policy is to promote social responsibility to share the burden of individual civil rights limitations to support vulnerable and discriminated groups.

This paper identifies new categories of NIP's side effects not confirmed by the previous studies namely the need (1) of intermediaries' support for egovernance functions execution, and (2) protection of the fundamental civil and human rights. Our study indicates the crucial role of adopting a mixed humanIT approach toward e-service provision to avoid the digital divide in priori [52]. Moreover, this problem is of particular importance to the elders of urban areas, where social facilities face a higher number of elders [38]. Our study indicates real data-based, short-term priorities of public policy such as respect for civil rights, enabling intermediary support, a necessity to build immunization awareness building and mitigating trust. Finally, our study presents a unique visualization of the distribution of the categories of the side effects of NIP implementation for seniors to e-governance functions.

The results point to guidelines and recommendations to policymakers and public health professionals regarding counteracting the side effects of national immunization programs for seniors. First, to undertake an extensive informational policy using adequate marketing streams to mitigate distrust and build seniors awareness. Second, to use e-government to strengthen networking, inter-departmental and adaptive governance of public intermediaries to support elders' immunization. Third, to provide data governance among governments, social and health care facilities and non-governmental organizations or individuals, engaged in elders support. Fourth, to provide good legislation guaranteeing civil liberties backed by a wide-ranging information campaign. Six, to shape, build, and strengthen the sense of social responsibility through extensive social campaigns.

\section{Conclusions}

This study aimed to scientifically recognize the issue of seniors' inclusion in NIP that heavily relies on e-government and services. This study adds to existing literature the analysis of the side effects of NIP for seniors according with four e-governance functions, namely protective, organizational, informational and transactional. Our research uncovered a rich catalogue of the side effects of NIP for seniors and provides the visualization of the importance of each e-governance function responding to the side effect categories. The results indicate a priority of civil rights protection, and institutional support of intermediaries to benefit ehealth services. We formulate guidelines and recommendation for policymakers and e-health professionals.

One of the limitations of this study is a lack of comparative analysis of policy action undertaken by various EU State Members toward implementation of NIPs regarding the elders. Since the effectiveness of particular State Members varies, sharing good practices and experience is vital. Future research should concentrate on adopting an institutional approach toward the investigation of intermediaries in e-government services provision to the elders. The second direction of future research may focus on the adoption of the agency theory to understand and deeply revise the mechanism behind counteracting the digital divide to seniors. 


\section{References}

[1] J. C. Bertot and P. T. Jaeger, "User-centered egovernment: Challenges and benefits for government Web sites," Gov. Inf. Q., vol. 23, no. 2, pp. 163-168, 2006.

[2] G. Juell-Skielse, C.-M. Lönn, and T. Päivärinta, "Modes of collaboration and expected benefits of inter-organizational E-government initiatives: A multi-case study," Gov. Inf. Q., vol. 34, no. 4, pp. 578-590, 2017.

[3] J. M. Wortham et al., "Characteristics of Persons Who Died with COVID-19 - United States, February 12-May 18, 2020," MMWR. Morb. Mortal. Wkly. Rep., vol. 69, no. 28, pp. 923-929, Jul. 2020.

[4] "Older Adults and COVID-19 | CDC." [Online]. Available: https://www.cdc.gov/coronavirus/2019ncov/need-extra-precautions/older-adults.html. [Accessed: 15-Jun-2021].

[5] K. Bagchi, "Factors Contributing to Global Digital Divide: Some Empirical Results," J. Glob. Inf. Technol. Manag., vol. 8, no. 3, pp. 47-65, 2005.

[6] R. L. Soiza, C. Scicluna, and E. C. Thomson, "Efficacy and safety of COVID-19 vaccines in older people," Age and ageing, vol. 50, no. 2. NLM (Medline), pp. 279-283, 26-Feb-2021.

[7] “COVID-19 Vaccine Tracker | European Centre for Disease Prevention and Control.".

[8] M. Zhang, P. Zhao, and S. Qiao, "Smartnessinduced transport inequality: Privacy concern, lacking knowledge of smartphone use and unequal access to transport information," Transp. Policy, vol. 99, pp. 175-185, Dec. 2020.

[9] OECD, "Understanding the digital divide," $O E C D$ Digital Economy Papers, no. 49. OECD Publishing, Paris, p. , 2001.

[10] R. Cullen, "The digital divide: a global and national call to action," Electron. Libr., vol. 21, no. 3, pp. 247-257, Jan. 2003.

[11] E. Ferro, N. C. Helbig, and J. R. Gil-Garcia, "The role of IT literacy in defining digital divide policy needs," Gov. Inf. Q., vol. 28, no. 1, pp. 3-10, 2011.

[12] B. J. Blažič and A. J. Blažič, "Overcoming the digital divide with a modern approach to learning digital skills for the elderly adults," Educ. Inf. Technol., vol. 25, no. 1, pp. 259-279, 2020.

[13] M. Finger and G. Pécoud, "From e-Government to e-Governance? Towards a Model of e-

Governance," in Proceedings of the 3rd European Conference on E-Government - ECEG, 2003, pp. 119-130.

[14] J. Rose, J. Holgersson, and E. Söderström, "Digital Inclusion Competences for Senior Citizens: The Survival Basics," in Lecture Notes in Computer Science (including subseries Lecture Notes in Artificial Intelligence and Lecture Notes in Bioinformatics), 2020, vol. 12219 LNCS, pp. 151-163.

[15] S. E. Peacock and H. Künemund, "Senior citizens and Internet technology," Eur. J. Ageing, vol. 4, no. 4, pp. 191-200, 2007.

[16] C. W. Phang, J. Sutanto, A. Kankanhalli, Y. Li, B. C. Y. Tan, and H. H. Teo, "Senior citizens' acceptance of information systems: A study in the context of e-Government services," IEEE Trans. Eng. Manag., vol. 53, no. 4, pp. 555-569, Nov. 2006.

[17] R. Nacheva and M. Bakaev, "Elder users' experience evaluation of bulgarian and russian egovernment websites," in Economic Science, education and the real economy: Development and interactions in the digital age, 2020, no. 1, pp. 241-256.

[18] L. Abad-Alcalá, C. Llorente-Barroso, M. SánchezValle, M. Viñarás-Abad, and M. Pretel-Jiménez, "Electronic government and online tasks: Towards the autonomy and empowerment of senior citizens," El Prof. la Inf., vol. 26, no. 1, pp. 34-42, 2017.

[19] V. Botrić and L. Božić, "The digital divide and Egovernment in European economies," Econ. Res. Istraz., 2020.

[20] S. AlAwadhi and A. Morris, "Factors influencing the adoption of e-government services," J. Softw., vol. 4, no. 6, pp. 584-590, 2009.

[21] A. Ko, T. Molnar, and B. Matyus, "A User-centred Design Approach for Mobile- Government Systems for the Elderly," in International Conference on Software, Knowledge Information, Industrial Management and Applications, SKIMA, 2019, vol. 2018-December.

[22] G. M. Van Jaarsveld, "The Effects of COVID-19 Among the Elderly Population: A Case for Closing the Digital Divide," Front. psychiatry, vol. 11, 2020.

[23] M. Janssen and H. Van Der Voort, “Adaptive governance: Towards a stable, accountable and responsive government." Elsevier, 2016.

[24] T. Janowski, T. A. Pardo, and J. Davies, "Government information networks-mapping electronic governance cases through public administration concepts." Elsevier, 2012.

[25] T. Janowski, "Digital government evolution: From transformation to contextualization," Gov. Inf. Q., vol. 32, no. 3, pp. 221-236, 2015.

[26] M. Janssen and E. Estevez, "Lean government and platform-based governance-Doing more with less," Gov. Inf. Q., 2013.

[27] S. Saxena, "Drivers and barriers towards re-using open government data (OGD): a case study of open data initiative in Oman," Foresight, vol. 20, no. 2, pp. 206-218, 2018.

[28] L. Anthopoulos, C. G. Reddick, I. Giannakidou, and N. Mavridis, "Why e-government projects fail? An analysis of the Healthcare. gov website," Gov. Inf. Q., vol. 33, no. 1, pp. 161-173, 2016.

[29] J. C. Bertot, P. T. Jaeger, and C. R. McClure, "Citizen-Centered e-Government Services: Benefits, Costs, and Research Needs," in Proceedings of the 2008 International Conference 
on Digital Government Research, 2008, pp. 137142.

[30] European Commission, "Commision Decision of 18.6.2020 approving the agreement with Member States on procuring Covid-19 vaccines on behalf of the Member States and related procedures." 2020.

[31] G. G. Ali et al., "Public Perceptions about COVID-19 Vaccines: Policy Implications from US Spatiotemporal Sentiment Analytics," Available SSRN 3849138, 2021.

[32] A. Hussain et al., "Artificial intelligence-enabled analysis of public attitudes on facebook and twitter toward covid-19 vaccines in the united kingdom and the united states: Observational study," $J$. Med. Internet Res., vol. 23, no. 4, p. e26627, 2021.

[33] A. Saibene, M. Assale, and M. Giltri, "Addressing digital divide and elderly acceptance of medical expert systems for healthy ageing," in CEUR Workshop Proceedings, 2020, vol. 2804, pp. 1424.

[34] K. Lam, A. D. Lu, Y. Shi, and K. E. Covinsky, "Assessing telemedicine unreadiness among older adults in the United States during the COVID-19 pandemic," JAMA Intern. Med., vol. 180, no. 10, pp. 1389-1391, 2020.

[35] S. Kurniawan, "Older people and mobile phones: A multi-method investigation," Int. J. Hum. Comput. Stud., vol. 66, no. 12, pp. 889-901, Dec. 2008.

[36] B. Niehaves and R. Plattfaut, "What is the issue with internet acceptance among elderly citizens? Theory development and policy recommendations for inclusive E-government," Lect. Notes Comput. Sci. (including Subser. Lect. Notes Artif. Intell. Lect. Notes Bioinformatics), vol. 6228 LNCS, pp. 275-288, 2010.

[37] D. Castilla et al., "Teaching digital literacy skills to the elderly using a social network with linear navigation: A case study in a rural area," Int. J. Hum. Comput. Stud., vol. 118, pp. 24-37, Oct. 2018.

[38] A. Ramsetty and C. Adams, "Impact of the digital divide in the age of COVID-19," Journal of the American Medical Informatics Association, vol. 27, no. 7. Oxford University Press, pp. 11471148, 01-Jul-2020.

[39] R. Cozma, "John H. Parmelee and Shannon L. Bichard. Politics and the Twitter Revolution: How Tweets Influence the Relationship Between Political Leaders and the Public," Mass Commun. Soc., vol. 16, no. 3, pp. 460-463, May 2013.

[40] Press, " $2,6 \mathrm{mln}$ polskich seniorów korzysta $\mathrm{z}$ Internetu, wolą Twitter od Facebooka,” 2015. [Online]. Available: https://www.press.pl/tresc/39971,2_6-mlnpolskich-seniorow-korzysta-z-internetu_-wolatwitter-od-facebooka. [Accessed: 19-Aug-2021].

[41] A. Ceron and F. Negri, "The 'Social Side' of Public Policy: Monitoring Online Public Opinion and Its Mobilization During the Policy Cycle,"
Policy and Internet, vol. 8, no. 2, pp. 131-147, 2016.

[42] M. Thelwall, "Can Twitter Give Insights into International Differences in Covid-19

Vaccination? Eight countries' English tweets to 21 March 2021," arXiv Prepr. arXiv2103.14125, 2021.

[43] G. Bello-Orgaz, J. Hernandez-Castro, and D. Camacho, "Detecting discussion communities on vaccination in twitter," Futur. Gener. Comput. Syst., vol. 66, pp. 125-136, 2017.

[44] A. Ojo and N. Rizun, "Structural and Temporal Topic Models of Feedbacks on Service Quality-A Path to Theory Development?," in AMCIS 2020 Proceedings. 15, 2020.

[45] Y. Chen, S. Brook, S. Skiena, and S. Brook, "Building Sentiment Lexicons for All Major Languages," pp. 383-389, 2014.

[46] K. M. Ehrenberg, The functions of law. Oxford University Press, 2016.

[47] S. Hubregtse, "The digital divide within the European Union," New Libr. World, vol. 106, no. 3/4, pp. 164-172, Jan. 2005.

[48] Y. Mizrachi, S. Shahrabani, M. Nachmani, and A. Hornik, "Obstacles to using online health services among adults age 50 and up and the role of family support in overcoming them," Isr. J. Health Policy Res., vol. 9, no. 1, pp. 1-10, 2020.

[49] M. Vozikaki, M. Linardakis, K. Micheli, and A. Philalithis, "Activity Participation and Well-Being Among European Adults Aged 65 years and Older," Soc. Indic. Res., vol. 131, no. 2, pp. 769795, 2017.

[50] M. Janssen, P. Brous, E. Estevez, L. S. Barbosa, and T. Janowski, "Data governance: Organizing data for trustworthy Artificial Intelligence," Gov. Inf. Q., vol. 37, no. 3, p. 101493, Jul. 2020.

[51] L. Zheng, W. M. Kwok, V. Aquaro, and X. Qi, "Digital government, smart cities and sustainable development," ACM Int. Conf. Proceeding Ser., vol. Part F1481, pp. 291-301, 2019.

[52] M. Janssen and B. Klievink, "Do we need intermediaries in e-government? Intermediaries to create a demand-driven government," 14th Am. Conf. Inf. Syst. AMCIS 2008, vol. 3, pp. 19921999, 2008.

[53] P. Rossel and M. Finger, "Conceptualizing EGovernance," in 2020 Fourth International Conference on Inventive Systems and Control (ICISC), 2020, pp. 186-191.

[54] N. Helbig, J. R. Gil-García, and E. Ferro, "Understanding the complexity of electronic government: Implications from the digital divide literature," Gov. Inf. Q., vol. 26, no. 1, pp. 89-97, 2009.

[55] O. Asan, A. E. Bayrak, and A. Choudhury, "Artificial intelligence and human trust in healthcare: focus on clinicians," J. Med. Internet Res., vol. 22, no. 6, p. e15154, 2020. 